\section{APROXIMAÇÕES DA AUTOPOIESE COM A GEOGRAFIA HUMANISTA}

Henrique Fernandes Moreira Neto'

\section{INTRODUÇÃO}

O lugar é um dos temas fundamentais da geografia contemporânea e a Geografia Humanista colaborou especialmente para seu desenvolvimento, trazendo contribuições da fenomenologia, do existencialismo e da psicologia (HOLZER, 1992; TUAN, 2013). Estas contribuições têm produzido repercussões ontológicas, levando à reflexão sobre a condição humana e o próprio sentido ontológico da experiência geográfica (RELPH, 2012; MARANDOLA JR., 2012)

A Geografia Humanista fez isso muito centrada na relação homemmeio, pois "o conhecimento geográfico, enquanto essência do relacionamento homem-meio, é um destes conhecimentos que compõem nossa realidade multifacetada" (MARANDOLAJR., 2010a, p. 15). A atenção parece estar concentrada no meio e suas características, mas como contemplar a natureza propriamente biológica e orgânica destes seres humanos (homens e mulheres) que somos?

O biólogo Humberto Maturana, empenhado em oferecer explicações abrangentes sobre o que é o conhecimento e como conhecemos, percebe a impossibilidade de tal explicação caso antes não entenda o que é o ser humano, biológica e culturalmente falando e como ele conhece. Surge então a teoria da Autopoiese; uma explicação do que

1 Geógrafo pela Universidade Estadual de Santa Cruz (UESC). Bolsista Treinamento Técnico 3 FAPESP. Laboratório de Geografia dos Riscos e Resiliência (LAGERR), Faculdade de Ciências Aplicadas (FCA), Universidade Estadual de Campinas (Unicamp). moreirah.neto@hotmail.com.

$\gtrsim$ Rua Pedro Zaccaria, 1300. Faculdade de Ciências Aplicadas da Unicamp. Limeira, SP. $13484-350$. seja o viver como ato de conhecer dos seres vivos. Um latente vir-aser fenomenológico dos seres vivos em geral, e de nós humanos em particular, que depende do meio para permitir o fluir da experiência que é o viver, dotando o espaço de identidade e autenticidade. (MATURANA, 2001)

Marandola Jr. (2010b, p. 1), quando discorre sobre identidade e autenticidade dos lugares, aponta que Edward Relph busca "fundamentos fenomenológicos para a Geografia", ao passo que entende lugar como fenômeno. Logo, Dartigues (2008, p. 32) nos aponta que, "para alcançar a essência [de lugar], não se trata [aqui] de comparar e de concluir, mas de reduzir, isto é, de purificar o [esse] fenômeno de tudo que comporta de inessencial, de 'fático', para fazer aparecer o que lhe é essencial".

O que será considerado "inessencial" não exclui ou extingue a complexidade do lugar, mas, apenas evita que essa complexidade funcione como cortina de fumaça, impedindo-nos de enxergar e compreender o lugar - essa compreensão por sua vez possibilitará a audaciosa resposta à pergunta: que é lugar?

Como concluiu Holzer (1999) em seu artigo sobre lugar, é necessário um retorno à ontologia da Geograficidade e uma análise da importância do lugar para a constituição da própria Geografia. Eric Dardel, geógrafo francês, foi quem melhor fez isso, expressando todo o sentido existencial do geográfico no seu conceito de geograficidade (DARDEL, 2011).

Nossa proposta é buscar uma conexão entre os aspectos biológicoculturais (a Autopoiese de Maturana) e a ontologia fenomenológica (a geograficidade de Dardel), constituindo o que poderíamos chamar de Autopoiese Geográfica, centrada em uma compreensão autopoiética e fenomenológica do lugar como fato na existência e expressão na experiência da relação homem-meio. O resultado é uma compreensão autopoiética da geograficidade dardeliana, permitindo 
a abertura de mais caminhos para reflexão sobre o lugar na geografia contemporânea.

\section{REALIDADE GEOGRÁFICA: O ESPAÇO E O HUMANO}

Humberto Maturana afirma que "a ciência é uma atividade humana, [logo] qualquer ação que nós cientistas realizamos ao fazer ciência tem validade e significado, como qualquer outra atividade humana, apenas no contexto de coexistência humana no qual surge" (MATURANA, 2001, p. 132). Não se trata de a ciência ser exata ou não, pois mesmo antes da preocupação dos geógrafos com uma Geografia que aponte uma realidade objetiva independente de quem a observa, como por exemplo, a descrição e análise do meio ambiente físico, "a história mostra uma Geografia em ato, [...] uma relação concreta que liga o homem à Terra" (DARDEL, 2011, p. 1). O contexto dessa coexistência, ao qual nos dispomos, é a consideração de que, mesmo nas ciências ou no cotidiano, "o homem se sinta e se saiba ligado à Terra como ser chamado a se realizar em sua condição terrestre" (DARDEL, 2011, p. 33).

A Geografia, segundo orientação de Dardel (2011), não deve ser um conhecimento sobre algo, pois antes é uma realidade. A realidade geográfica é fato pelo modo de existência do homem, o modo humano de ser. É a sua geograficidade que abriga e é abrigada, envolvendo no movimento espiral do tempo o homem e o espaço. A partir daqui o caminho do nosso pensamento e, consequentemente, do nosso texto, divide-se para depois se reencontrar. Comecemos pelo espaço.

\section{O ESPAÇO}

O espaço no âmbito da Geografia Humanista é compreendido na dimensão existencial; é o espaço do corpo e suas extensões, assim como o espaço da mente e do viver cotidiano. "O espaço é o real e o imaginário" (SILVA, 2000, p. 18) e para além de realidade e imaginação, o pensar sobre espaço envolve o pensar sobre vivência, experiência e significação.

Das diferenciações do espaço propostas por Dardel (2011), denotamos sua intenção de chamar de espaço geográfico todo tipo de condição espacial analisada. Ao contrário de Edward Relph que, segundo Holzer (1999, p. 71), afirma ser o espaço vivido o invólucro que "contém o espaço sagrado e o espaço geográfico". Para Dardel (2011) o espaço geográfico é, enquanto hábitat e habitante do homem, espaço material, espaço telúrico, espaço aquático, espaço aéreo e espaço construído. Quando introduz o espaço geográfico, o autor expõe sobre mais uma faceta da Geograficidade, essa ligação do homem à Terra, deixando sempre clara a sua condição humana:

Se a Geografia oferece à imaginação e à sensibilidade, até em seus voos mais livres, o socorro de suas evocações terrestres (terriennes), marinhos ou atmosféricos, também, sempre espontaneamente, a experiência geográfica, tão profunda e tão simples, convida o homem a dar à realidade geográfica um tipo de animação e de fisionomia em que ele revê sua experiência humana (DARDEL, 2011, p. 6 - grifo do autor).

No "espaço material" somos lembrados de nossa condição física, concreta onde "o espaço geográfico é talhado na matéria ou diluído em uma substância móvel ou invisível" (DARDEL, 2011, p. 7). Não é apenas a floresta ou a montanha, o rio ou o lago, o país ou a cidade; é um espaço significado e posto à prova a partir das concepções humanas, pois se origina em nós todo e qualquer tipo de referência, escalar ou não, para fazer menção, uso e transformação desse espaço que, por sua vez, não é fechado em si e sim dinâmico à medida que provoca o homem a viver o distanciamento enquanto materialidade (DARDEL, 2011). O espaço geográfico concreto é "sem dúvida o 
espaço onde se desenvolve a existência, porque ela é, em essência, extensão" (DARDEL, 2011, p.13). Essa extensão, no entanto, não deve se confundir com o espaço telúrico.

O espaço geográfico enquanto telúrico expõe a profundidade do espaço material dada na "experiência imediata, primitiva, onde experimentamos a intimidade material da 'crosta terrestre', um enraizamento, uma espécie de fundação da realidade geográfica" (DARDEL, 2011, p.15 - grifo do autor). É também movimento, é o solo ondulado, é terreno acidentado; é o "telurismo virulento nos fenômenos da ação" (DARDEL, 2011, p. 19). Toda a variedade de formas da Terra e toda sua composição comprovam a facticidade da realidade geográfica à qual somos submetidos desde que nos tornamos seres conscientes. $O$ espaço construído enquanto hábitat do homem é o que revolve o ciclo de nossa presença no planeta Terra. É a casa e a cidade que então ditam o modo de ser do homem.

Este entendimento será importante para pensar a Autopoiese Geográfica, vinculada ao modo de ser do homem, transformando o meio e esse meio transformando o homem e, então, essa relação se perpetua no espaço-tempo, conservando as essências de tudo o que garantirá essa perpetuação. É o que fundamenta o espaço geográfico enquanto espaço construído; é a "exteriorização da mobilidade fundiária do homem em sua relação existencial com a Terra" (DARDEL, 2011, p. 30). Eis a Geograficidade.

Entendidos esses espaços fenomênicos, resta-nos o homem, o ser humano. Esse é nosso segundo caminho. Mas, por que a Geografia deveria se preocupar com isso?

\section{A CIÊNCIA, O BICHO-HOMEM E O MODO HUMANO DE SER}

Toda ciência é, inicialmente, uma explicação reformulada da experiência ou fenômeno feito por um observador, observando o observar ainda que dele mesmo, enquanto ser humano, biológico. Logo, "tudo que é dito, é dito por um observador a outro observador que pode ser ele ou ela mesma na linguagem" (MATURANA, 2001, p. 36).

A produção do conhecimentosurge a partirdo próprio conhecimento, proporcionado pela condição biológica da cognição e da articulação e coordenação do fluxo de símbolos, significações e pensamentos que ganham distinção através da linguagem, na conversação (MATURANA, 2001).

A exaltação da condição biológica, orgânica, é ilustrada a partir de uma situação posta por Maturana (2001, p. 31) quando discute a validade das explicações científicas e, consequentemente, nossa existência e consciência do mundo: "E pode acontecer de, quando estarmos andando pela rua, cair um tijolo na cabeça de qualquer um de nós. Caímos no chão e acabou-se toda nossa dinâmica cognitiva; a capacidade cognitiva acaba quando o tijolo me destrói o cérebro", então, nós temos que levar em consideração a biologia, afinal, somos humanos falando do modo humano de estar sobre a Terra.

Um ser vivo, de acordo com Maturana (2001), é um sistema determinado estruturalmente cuja finalidade primeira é conservar sua organização e adaptação. Ainda de acordo com o autor, esse sistema é um conjunto de elementos acoplados de uma forma que tudo que acontece ao sistema, a esse conjunto, depende então de como ele está sendo feito e que consequentemente, em sua interação com outros sistemas, a saber o próprio homem ou o meio, desencadeiam mudanças que estão determinadas neles mesmos. Isto faz parte do cotidiano, ao passo que estamos por demais envolvidos nessa determinação. O que ilustra essa colocação é quando

Tratamo-nos uns aos outros como sistemas determinados estruturalmente: queixamo-nos quando o outro não se 
comporta de determinada maneira. "Mas eu já te disse..." "já te disse que...". Cada vez que um diz ao outro "já te disse", no fundo está lhe dizendo: "Você deveria haver se transformado de uma certa maneira específica, porque eu já desencadeei em você as mudanças correspondentes." [e daqui vem nossa complexidade humana, pois] nem sempre desencadeamos no outro a mesma coisa. [...]. (MATURANA, 2001, p. 74).

Organismo e meio se alteram mutuamente e simultaneamente, o que proporciona a compreensão da evolução, não só dos organismos como também de seus meios, seus espaços. Essa é uma relação necessária uma vez que nos damos conta de estarmos vivos sobre um planeta num sistema de constelações e é necessária quando admitimos que não poderia ter sido de outra forma. Maturana chama esse fenômeno de deriva estrutural: quando se está à deriva não se possui timão ou remos e os motores da embarcação não funcionam, deixando então o sujeito entregue à sorte das ondas e dos ventos. $\mathrm{O}$ guarda costeiro calcula, então, o possível local onde o barco pode estar e soma ao tempo que levará para fazer o resgate. Esse espaço entre análise da situação e chegada ao local é somado à dinâmica ondasbarco-vento para determinar onde o barco estará quando for chegado o momento do resgate (MATURANA, 2001).

Igualmente dinâmica é nossa história enquanto organismos nesse oceano existencial, que é a Terra desde sua gênese. "As mudanças estruturais que ocorrem não são determinadas pelas circunstâncias do meio, mas são contingentes com elas, porque o meio apenas desencadeia no ser vivo mudanças estruturais" (MATURANA, 2001, p. 81). Essa interação também ocorre entre os seres, e igualmente um ser desencadeia mudanças estruturais no outro. Não podemos esquecer a característica fundamental da conservação de sua organização e de sua adaptação feita pelos seres. Essa relação entre o meio e entre os outros é chamada de comportamento, e o que acontece nessa relação é chamado de conduta (MATURANA, 2001). Surge, então, a linguagem como uma co-deriva, uma coordenação de condutas.

Não requer nada especial, e sim interações [...], suficientemente recorrentes, e uma diversidade interna suficiente, de modo que a diversidade de estados de A e B (Figura 1) possam ser comparáveis às circunstâncias de coordenações de conduta nas quais se encontram (MATURANA, 2001, p. 85).

Eis a história dos hominídeos, onde A e B são os hominídeos e C é o meio (Figura 1). Com o tempo sendo indicado pela linha pontilhada há a representação do espaço da relação homem-meio e essa adaptação por acoplamento vai além da forma. Uma sucessão de interações no espaço e no tempo que provocam mudanças no meio e no outro, configurando um acoplamento por adaptação, como na relação $A, B$ e C. Então, tudo está em relação com o fato do encontrar no espaço do meio. Não falamos mais de espaço ou do meio e sim do espaço

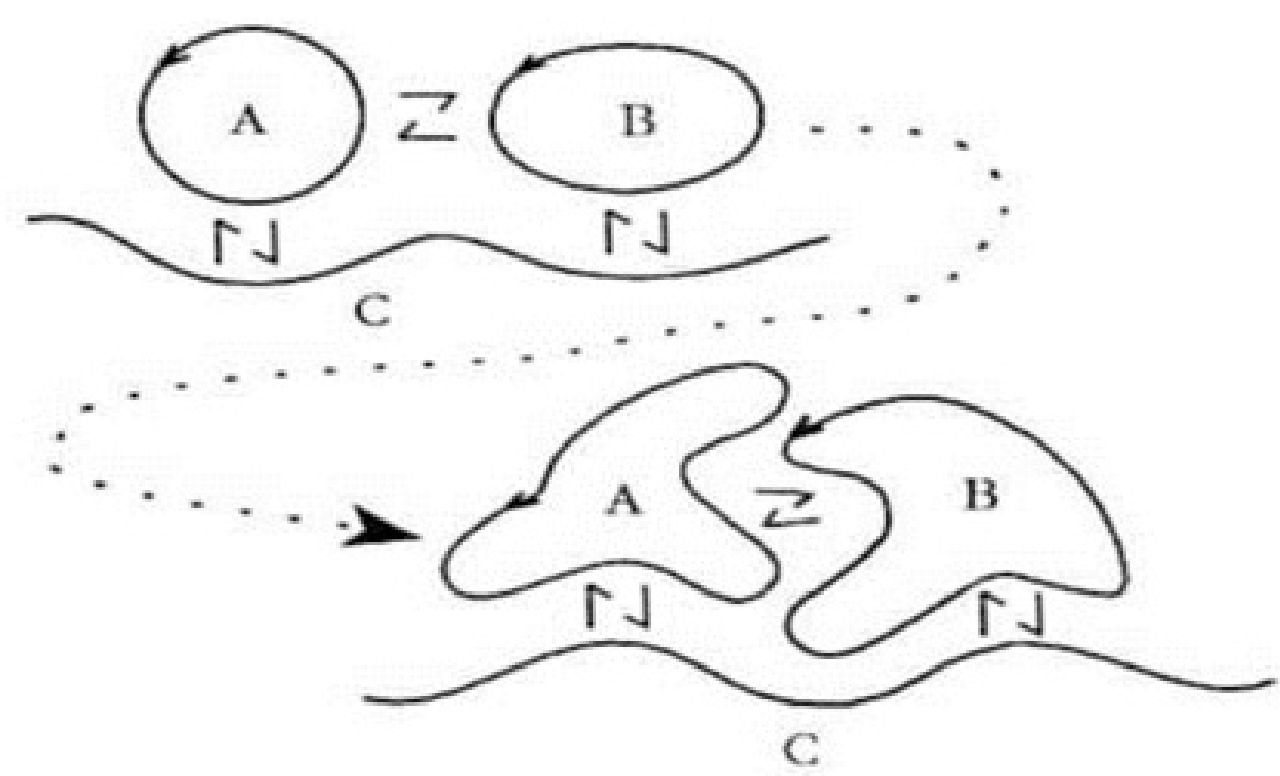

Figura 1 - Esquema da relação (homem $\mathrm{x}$ homem) x meio. Fonte: Adaptado de Maturana (2001). 
do meio, como uma co-deriva à deriva estrutural já apontada, uma coordenação de coordenações de condutas.

Não é apenas a interação que conta, mas sim sua história ou, dito de outra maneira, a forma pela qual ela se dará. Temos então a primeira indicação do que é o humano; como uma consequência da relação direta com o outro e com o meio, na linguagem e na aceitação. Para que se dê a interação é preciso de uma disposição inicial, quer dizer, uma emoção, que acontece e não possui um explicar específico inicial, pois é uma característica biológica.

Alguém passa pela rua e diz: "olha o gato..." e passa ao largo. Mas outra pessoa passa e diz: "Olha que gatinho lindo", e o pega. As disposições estruturais dessas duas pessoas são distintas. No primeiro caso, há um gato; um encontro transitório e a coisa termina. Na outra não. A interação inicial desencadeia uma mudança estrutural tal que abre espaço para uma segunda interação e assim sucessivamente - e a pessoa pega o gato e o leva para casa (MATURANA, 2001, p. 86).

Ainda assim é necessário existir a disposição estrutural da aceitação do outro na convivência. Essa aceitação funciona tanto para sistemas animados quanto para inanimados. A pessoa que não pegou o gato não o aceitou em sua convivência. O gato por sua vez pode não aceitar a convivência com a pessoa que o pegou ou não se adequar ao meio no qual estará, logo irá embora. Precisamos, então, da disposição para a perpetuação da interação, tanto no gato quanto no seu novo dono. "O gato desencadeia uma mudança estrutural que o coloca de tal maneira que se orienta para interagir de novo com a pessoa e a pessoa se orienta para interagir de novo com ele e etc. Isto é o que eu chamo de amor" (MATURANA, 2001, p. 86).

Para Maturana (2001) o ser humano é a disposição corporal e mental na aceitação do outro no espaço da convivência e na linguagem. Com isso ele quer tirar o amor da ideia especial à qual está jogado. Ainda explica que quando estabelecemos a conversação e por ela estar dentro da linguagem, a palavra é ação e então tudo vem à existência no espaço. Não estamos mais falando de meio pois este já é constituinte do homem ao passo que constituição. Falamos de espaço. Esse também é o espaço das interações entre os seres humanos. Apenas na linguagem é possível distinguir o propósito de estarmos vivos, caso contrário, não teríamos experimentado o desenvolvimento da consciência e da razão.

Viemos, então, à frase inicial desse caminho, que o humano não pode ser concluído num conceito ou numa definição. Podemos considerar que esta é a realidade geográfica: o humano como um modo de ser dentre tantos outros modos de ser de todos os outros seres e coisas que habitam a Terra e todos ao mesmo tempo acoplados, conectados, ligados à Terra; uma Geograficidade.

\section{QUE É LUGAR?}

Relph (2012, p. 20) quando discorre sobre as possíveis razões da necessidade de estudar lugar, tanto como conceito quanto como fenômeno, afirma que desde 1990 não só a Geografia, mas outras ciências como psicologia, sociologia, antropologia e arquitetura, por exemplo, tem promovido lugar como tema importante na interpretação da modernidade. Aponta ainda que "uma vez que lugar é o fenômeno da experiência, era apropriado que ele fosse explicado por meio de uma rigorosa abordagem fenomenológica que havia sido desenvolvida por Husserl e Heidegger". Essa abordagem é, pois, o que fundamenta, também, os trabalhos do próprio autor.

Para Relph 
Lugares são fusões da ordem humana e natural e são centros significantes de nossa experiência imediata do mundo. Eles são definidos menos por locaisúnicos, paisagem e comunidade e mais pela focalização de experiências e intenções para configurações específicas. (RELPH, 1976, p. 141) ${ }^{2}$

Se encararmos lugar como essa fusão entre a ordem humana (homem) e a ordem natural (meio), mais uma vez encontramos correspondência na Geograficidade para encararmos o homem como lugar. Lugar, então, não é um conceito ou abstração. Tendo a experiência humana como ponto de partida, pela consciência de si mesma, do outro e do mundo, "lugares são fenômenos do mundovivido diretamente experienciados" (RELPH, 1976, p. 141). ${ }^{3}$

É com essa cotidianidade que nos preocupamos quando trazemos contribuições distintas para a compreensão desse existir, humano, no mundo onde "o homem-sujeito identifica-se com seu corpo e sua situação, estabelecendo com eles um intercâmbio que se poderia definir como prático-afetivo" (NOGUEIRA, 2008, p. 134).

Quando Dartigues (2008, p. 116) interpreta essa unidade que é o mundo e a existência, ela se torna compreensível quando consideramos o vai-e-vem existencial que é o homem como ser-no-mundo, pela "facticidade de sua existência". A manifestação da presença do mundo e do outro é que marca o caráter intencional da consciência humana, em sua facticidade, conferindo-lhe o telurismo necessário para ser humano.

A experiência do corpo-consciência que o homem é com o espaço é que configura a existência numa Autopoiesis. O homem, humano

2 "Places are fusions of human and natural order and are the significant centres of our immediate experiences of the world. They are defined less by unique locations, landscape, and communities than by the focusing of experiences and intentions onto particular settings".

3 "places are directly experienced phenomena of the lived-world". em seu modo de ser e seu ato de revelar com intencionalidade, "é sempre consciência-no-mundo, ligada indissociavelmente a ele pelo corpo" (NOGUEIRA, 2008, p. 135). Nossa facticidade corporal marca nosso ser-no-mundo em finitude e temporalidade à medida que nos humanizamos humanizando o mundo. Nogueira (2008) mostra que:

Em toda parte onde exerce sua presença o homem se manifesta como ser que tem ontologicamente como característica instaurar e manifestar sentido. Isso ele faz pelo próprio corpo que apresenta a dupla característica da reflexividade da consciência e a visibilidade própria do mundo (NOGUEIRA, 2008, p. 137 grifo do autor).

Em outras palavras e em nossa interpretação, é no fato de o homem ser lugar que ele consegue manifestar sentido, independentemente de seu tempo de vida. O ser humano possui o tempo como uma de suas facticidades e como uma limitação. É o tempo do ano quando a Terra completa uma volta em torno do Sol, é o tempo de vida de acordo com o tipo de vida que se tem. Tuan (2011, p. 12) mostra a relação entre espaço e tempo para explicar de que forma o lugar está ligado a essa relação e finalmente aponta a direção para pensar o que é lugar. "O lugar é pausa no movimento" e esse movimento "exige tempo e ocorre no espaço: eles exigem um campo espaço-temporal". O vai e vem existencial apontado por Dartigues (2008, p. 116) pode ser comparado ao "movimento pendular entre dois mundos" (EBERHARD, 1965 apud TUAN, 2011, p. 12). Em nossa consideração sobre lugar, um desses dois mundos é o próprio homem e o outro mundo é o meio.

O homem, humano em seu modo de ser, é então lugar pela configuração de sua própria natureza e que consequentemente é a natureza do lugar. É o pulsar ou o vai e vem existencial. Logo, é a existência do homem como esse núcleo, como o centro de fusão apontado por Relph (1976), fusão essa, que é também, de ideias, 
Aproximações da autopoiese com a geografia humanista

pensamentos, espaços, tempos e sentimentos, na malha existencial, que exerce influência sobre o espaço à medida que é influenciado por este espaço, num ciclo auto gerativo que leva tempo - Autopoiese Geográfica.

A consciência humana encarnada é o núcleo existencial que funde o que é de fora com o que é de dentro, numa Autopoiese Geográfica, acoplando essas várias realidades em um vai-e-vem existencial, gerando lugar no movimento desse pulsar, independentemente de onde o homem esteja.

Lugar é o aqui e o lá. É a cama, o quarto, a casa, a rua, o bairro, a cidade, o Estado, o país. É o carro, a estrada, o shopping, a praia, o céu, o espaço sideral. Lugar é o outro - a mãe, o pai, o amigo, o irmão. Lugar é onde o ser humano estiver, pois o enquanto houver, sobre a face daTerra, homens e mulheres de todas e quaisquer raças e idades, certamente existirão lugares. $\theta$

\section{REFERÊNCIAS}

ANDRADE, C. C. de. A Fenomenologia da Percepção a partir da Autopoiesis de Humberto Maturana e Francisco Varela. Griot-Revista de Filosofia, v. 6, n. 2, dezembro/2012, p. 98-121.

DARDEL, Eric. O Homem e a Terra: natureza da realidade geográfica. (Trad. Werther Holzer). São Paulo: Perspectiva, 2011.

DARTIGUES, André. O que é a Fenomenologia. São Paulo: Centauro, 2008.

HOLZER, Werther. O lugar na Geografia Humanista. Revista Território, Rio de Janeiro, ano IV, n. 7, jul/dez 1999, p. 67-78.
O método fenomenológico: humanismo e a construção de uma nova Geografia. In: ROSENDAHL, Z.; CORRÊA, R. L. (Org.). Temas e Caminhos da Geografia Cultural. Rio de Janeiro: EDUERJ, 2010.

MARANDOLA JR., Eduardo. Humanismo e Arte para uma Geografia do Conhecimento. Geosul, Florianópolis, v. 25, n. 49, jan./jun. 2010a, p. 7-26.

- Identidade e autenticidade dos lugares dos lugares: o pensamento de Heidegger em Place and Placelessness, de Edward Relph. In: XVI Encontro Nacional de Geógrafos - ENG, 16, 2010, Porto Alegre. Anais... Porto Alegre: AGB, 2010.

MATURANA, R. H. Cognição, Ciência e Vida Cotidiana (Trad. Cristina Magro, Victor Paredes). Belo Horizonte: Ed. UFMG, 2001.

NOGUEIRA, João Carlos. A Percepção como revelação do mundo: a fenomenologia de Merleau Ponty. In: CESAR, C. M.; BULCÃO, M. Sartre e seus Contemporâneos: ética, racionalidade e imaginário. Aparecida, SP: Ideias \& Letras, 2008. p. 131-146.

RELPH, Edward. Place and placelessness. Londres: Pion, 1976. 156p.

Reflexões sobre a emergência, aspectos e essência de lugar. In: HOLZER, W.; MARANDOLA JR. E.; OLIVEIRA, L. de. (Org.) Qual o Espaço do Lugar?: Geografia, epistemologia, fenomenologia. São Paulo: Perspectiva, 2012. p. 17-32.

SILVA, Armando C. A aparência, o ser e a forma (Geografia e Método). GEOgraphia, Niterói, ano II, n. 3, 2000.

TUAN, Yi-Fu. Espaço e lugar: a perspectiva da experiência. (Trad. Lívia de Oliveira) São Paulo: Difel, 1983.

Espaço, tempo, lugar: Um arcabouço humanista. Geograficidade, v. 1, n. 1, Inverno 2011, p.4-15.

Espaço e Lugar: a perspectiva da experiência. (Trad. Lívia de Oliveira) Londrina: EDUEL, 2013. 